Steven Moldin and John Rubenstein. This excellent collection of chapters on ASD, and on basic research relevant to ASD, provides few answers, but, I fear, better reflects the truth about our understanding of autism. A detailed and thorough examination of epidemiological studies by Eric Fombonne, for example, casts real doubt on the claim that the rate of ASD cases is increasing. Instead, he concludes that truly comparable time-trend data do not exist; until these are collected, changes in diagnostic criteria and practices, greater awareness and improved services may be sufficient to explain the increase in identified cases. And if there is no big rise in prevalence, there is no need to invoke a major environmental contribution.

Similarly, the idea that autism can be explained by damage to the limbic system (the 'social brain') is probably too simplistic. The chapter by Schumann, Bauman, Machado and Amaral reviews evidence from human and animal lesion studies. They suggest that the amygdala is not the seat of social processing, but instead plays a role in regulating fear behaviour, with knock-on effects exacerbating social deficits in autism. Indeed, many examples in the book illustrate how much more complex the story of autism is likely to be, including epigenetic regulation (not involving differences in the nucleotide sequence) through DNA methylation or chromatin remodelling.

Should we be despondent in the face of such complexity and the paucity of answers regarding the causes of autism? I think the book by Moldin and Rubenstein gives as much reason for hope as for despair. The chapters reflect the diverse tools being called into the service of understanding autism, including neuroimaging, animal models, even the use of neurotropic viruses, which attack the nervous system, to trace chains of synaptically linked neurons.

Parents, teachers, dinicians and researchers are all searching for explanations, for a story that will help us make sense of autism and show us how to help. Lathe's book tells a fascinating tale, but Moldin and Rubenstein's may be closer to the truth. After all, the one thing that all those who study autism agree on is that no one really understands autism.

Francesca Happé is a reader in cognitive neuroscience at the MRC Social, Genetic and Developmental Psychiatry Research Centre, Institute of Psychiatry, King's College London, London SES 8AF, UK.

\title{
Subterranean storage blues
}

\author{
Uncertainty Underground: Yucca Mountain \\ and the Nation's High-Level Nuclear Waste \\ edited by Allison M. Macfarlane \& \\ Rodney C. Ewing \\ MIT Press: 2006.416 pp. \$72, $€ 46.95$ (hbk); \\ $\$ 29, £ 18.95$ (pbk)
}

\section{Gordon MacKerron}

Earth scientists generally have strong views about the deep disposal of radioactive waste. They all agree that deep disposal is the safest option, and that several suitable geologies exist, but it is difficult to gain consensus about the safety of any specific site. Uncertainty Underground, edited by Allison Macfarlane and Rodney Ewing, displays these viewpoints clearly. The individual chapters are not only well-written but also broadly comprehensible, even to a social scientist such as me. All the authors - who belong mostly to the Earth-sciences community and work variously in academia, industry, govern-

ment and consultancy - are in favour of deep disposal. But they hold very different views on the suitability of the Yucca Mountain site in Nevada, which has been the chosen resting place for US high-level waste and spent nuclear fuel since 1987.

The editors have had an unusually strong influence on this collection. They selected authors and subjects to illustrate their main theme - that too much attention has been paid to the 'near-field' (broadly, the engineering of the repository and its contents) and not enough to the less-controllable issues of the geology and hydrogeology of Yucca Mountain and its surroundings.
The Yucca Mountain site is, in international terms, unique as a potential repository site because it is 'dry', being well below the surface of the mountain but, critically, well above the water table. Some authors argue that this 'advantage' is potentially problematic: hydrogeologists have concentrated on 'wet' sites, and have done little work on the hydrology of dry sites. Potentially major climatic, volcanic,

uncertain (transport in the saturated zone).

Another section covers waste packages and waste forms, for which the uncertainties seem considerably smaller (as the editors suggest) than for the geology and hydrogeology. However, a long-running debate rumbles on between advocates of glass versus ceramics as the best medium in which to contain highlevel wastes.

For social scientists, the sections on policy and uncertainty are especially interesting. The debates about the standard of 'proof' of safety over timescales of up to a million years are well and clearly presented. Particularly good are the sections on the distinction between risk (the probability of something going wrong, from which decision-making at least has a starting point) and the inevitable uncertainties over very long periods into the future, for which precise risk levels are unknown and probably unknowable. This raises the issues of ethics and the way the rights of distant generations are balanced against those of the near future, although these are not covered here.

Finally, on policy, it is clear that the choice of Yucca Moun-

seismic and other changes over periods of up to a million years in the future could in principle lead to substantially different hydrological regimes, with evident long-term safety implications.

Many of the papers in this volume therefore review specific issues of hydrology and thermohydrology at Yucca, such as the risk of hot upwelling water from the water table flooding the site in the future, radionuclide transport in the unsaturated zone, and contaminant transport in the saturated zone. Varying degrees of reassurance emerge from this hydrologybased set of papers, from virtually complete (with regard to hot upwelling) to much more tain, especially in the legislation of 1987 , is severely clouded by a lack of political legitimacy that may yet prove highly problematic. This book shows clearly that a site such as Yucca Mountain can probably be made safe enough if the geology is sufficiently well understood and married to the right engineering. But the question of whether it will be perceived by the public as a good site depends on a political process that has, at best, been poorly handled in the United States.

Gord on MacKerron is chair of the UK Committee on Radioactive Waste Management, and director of the Sussex Energy Group, SPRU, University of Sussex, Brighton BN1 9RH, UK. 